\title{
Prefácio à Seção Especial dos Tutoriais do SIBGRAPI'08
}

Sejam bem-vindos à seção especial dos tutoriais do SIBGRAPI 2008!

Os participantes do SIBGRAPI de 2008 tiveram a oportunidade de presenciar um conjunto excepcional de tutoriais que cobriram uma vasta gama de assuntos de interesse da comunidade.

Tivemos dois tutoriais introdutórios: o primeiro sobre o uso do OpenCV, uma biblioteca já estabelecida para desenvolvimento de aplicações em visão computacional, e o segundo sobre o uso de processamento de imagens para a elaboração de efeitos especiais.

Nossos tutoriais avançados foram também bem diversos. $O$ primeiro tratou sobre o uso de CUDA, uma nova linguagem desenvolvida pela NVIDIA para o uso das placas gráficas de última geração em problemas de computação geral, em aplicações de realidade aumentada.

Nosso segundo tutorial avançado lidou com o ajuste de superfícies utilizando pseudo-variedades parametrizadas. Desde a conferência, os autores deste tutorial publicaram o material em outras conferências e revistas, e acharam melhor disponibilizar o material do tutorial juntamente com estas publicações no portal do projeto, localizado em http://w3.impa.br/ /velho/ppm09/.

Desejamos então que todos aproveitem o material dos três tutoriais publicados aqui nesta seção.

Siome Klein Goldenstein Instituto de Computação, UNICAMP, Campinas-SP, Brazil siome@ic.unicamp.br

Anselmo Antunes Montenegro Instituto de Computação, UFF, Niterói-RJ, Brazil anselmo@ic.uff.br

Sibgrapi 2008 Tutorial Chairs 